\title{
Interdisciplinary, interinstitutional and international collaboration of family medicine researchers in Taiwan
}

Yi-Hsuan Lin, Yen-Han Tseng, Hsiao-Ting Chang, Ming-Hwai Lin, Yen-Chiang Tseng, Tzeng-ji Chen, Shinn-Jang Hwang

The family medicine researches flourished worldwide in the past decade. However, the collaborative patterns of family medicine publications had not been reported. Our study analyzed the collaborative activity of family medicine researchers in Taiwan. We focused on the types of collaboration among disciplines, institutions and countries. We searched "family medicine" AND "Taiwan" in address field from Web of Science and documented the disciplines, institutions and countries of all authors. We analyzed the collaborative patterns of family medicine researchers in Taiwan from 2010 to 2014. The journal's impact factor of each article in the same publication year was also retrieved. Among 1,217 articles from 2010 to 2014, interdisciplinary collaboration existed in 1,185 (97.3\%) articles, interinstitutional in 1,012 (83.2\%) and international in 142 (11.7\%). Public health was the most common collaborative discipline. All international researches were also interdisciplinary and interinstitutional. The United States (75 articles), the United Kingdom (21) and the People's Republic of China (20) were the top three countries with which family medicine researchers in Taiwan had collaborated. We found a high degree of interdisciplinary and interinstitutional collaboration of family medicine researches in Taiwan. However, the collaboration of family medicine researchers in Taiwan with family medicine colleagues of other domestic or foreign institutions was insufficient. The future direction of family medicine studies could focus on the promotion of communication among family medicine researchers. 


\section{Interdisciplinary, interinstitutional and international collaboration}

2 of family medicine researchers in Taiwan

3

4

5

6

7

8

9

10

${ }^{1}$ Division of Family Medicine, Taipei Hospital, Ministry of Health and Welfare, New Taipei City, Taiwan

2 Department of Family Medicine, School of Medicine, National Yang-Ming University, Taipei, Taiwan

${ }^{3}$ Chest Department, Taipei Veterans General Hospital, Taipei, Taiwan

${ }^{4}$ School of Medicine, National Yang-Ming University, Taipei, Taiwan

${ }^{5}$ Department of Family Medicine, Taipei Veterans General Hospital, Taipei, Taiwan

${ }^{6}$ Department of Surgery, Kaohsiung Veterans General Hospital, Pingtung Branch, Pingtung, Taiwan

${ }^{7}$ Institute of Hospital and Health Care Administration, School of Medicine, National Yang-Ming University, Taipei, Taiwan

Corresponding author: Prof. Tzeng-Ji Chen, Department of Family Medicine, Taipei Veterans

General Hospital, No. 201, Sec. 2, Shih-Pai Road, Taipei 112, Taiwan

Tel: +886228757458, Fax: +886228737901, E-mail: tjchen@vghtpe.gov.tw 


\section{ABSTRACT}

28 The family medicine researches flourished worldwide in the past decade. However, the

29 collaborative patterns of family medicine publications had not been reported. Our study analyzed

30 the collaborative activity of family medicine researchers in Taiwan. We focused on the types of

31 collaboration among disciplines, institutions and countries. We searched "family medicine"

32 AND "Taiwan" in address field from Web of Science and documented the disciplines,

33 institutions and countries of all authors. We analyzed the collaborative patterns of family

34 medicine researchers in Taiwan from 2010 to 2014. The journal's impact factor of each article in

35 the same publication year was also retrieved. Among 1,217 articles from 2010 to 2014,

36 interdisciplinary collaboration existed in 1,185 (97.3\%) articles, interinstitutional in 1,012

$37(83.2 \%)$ and international in $142(11.7 \%)$. Public health was the most common collaborative

38 discipline. All international researches were also interdisciplinary and interinstitutional. The

39 United States (75 articles), the United Kingdom (21) and the People's Republic of China (20)

40 were the top three countries with which family medicine researchers in Taiwan had collaborated.

41 We found a high degree of interdisciplinary and interinstitutional collaboration of family

42 medicine researches in Taiwan. However, the collaboration of family medicine researchers in

43 Taiwan with family medicine colleagues of other domestic or foreign institutions was

44 insufficient. The future direction of family medicine studies could focus on the promotion of 
45 communication among family medicine researchers. 


\section{INTRODUCTION}

48 Family physicians are the main providers of primary health care. Although in most countries

49 family physicians belong to the largest group of medical specialties, family medicine research

50 did not receive due attention (Bolon \& Phillips, 2010). Academic performance assessment by

51 SCI (Scientific Citation Index) and IF (impact factor) also affected the development of family

52 medicine research (Lin et al., 2006). To publish more papers in journals of higher IFs, in most

53 cases in other specialties or disciplines, many family medicine researchers tried to establish a

54 collaborative research network (Parchman, Katerndahl \& Larme, 2003). In the past decade,

55 publications from family medicine researchers did increase rapidly (Abdulmajeed, Ismail \&

56 Nour-Eldein, 2014; Lin et al., 2014). However, their patterns of collaboration have been rarely

57 analyzed.

58 The aim of the current study was to investigate the collaborative patterns of family medicine

59 researchers in Taiwan. Family medicine has become an official specialty in Taiwan since 1988

60 (Department of Health, Executive Yuan, 1988). Up to July 2015, there were 5,075 family

61 medicine specialists in Taiwan (Ministry of Health and Welfare, 2015). According to the

62 statistics in December 2013, the residency training programs for family medicine were carried

63 out in 83 hospitals with 493 attending physicians (Taiwan Association of Family Medicine, 2015).

64 We would analyze the collaborative activity of family medicine researchers in the recent 5 years. 
65 Instead of interpersonal aspect, the collaboration would be examined among disciplines,

66 institutions and nations. The descriptive analyses might carry implications for the future of

67 family medicine research.

68

69 MATERIALS AND METHODS

70 Subjects and data collection

71 We downloaded the records from Web of Science ${ }^{\circledR}$ with Science Citation Index Expanded (SCI)

72 and Social Science Citation Index (SSCI) databases in April 2015. The search criteria were

73 "family medicine" AND "Taiwan" in address. We analyzed only articles and excluded other

74 publication forms such as abstracts, letters, notes, news, editorials, meeting summaries and

75 reviews. As long as a family medicine physician was listed in co-author in an article, we enrolled

76 this article and analyzed its collaborative patterns. Our search results might include papers in

77 which family medicine researchers in other countries collaborated with non-family medicine

78 researchers in Taiwan. These papers were manually screened out.

80 Study design

81 In each article, we documented the disciplines, institutions and countries of all authors in

82 addition to publication year, journal's name and IF. We also identified the articles with family 
83 medicine researchers as the first or corresponding authors. The journal's IF of each article in the

84 same publication year was retrieved from Web of Science. Because the Journal Citation Reports

852014 was not available at the time of study execution, the IFs of articles in 2014 were substituted

86 with the IFs in 2013.

87 In addition to the analysis of publication trend of family medicine researchers in Taiwan from

881993 to 2014, we calculated the interdisciplinary, interinstitutional and international

89 collaborative patterns of family medicine researchers in Taiwan from 2010 to 2014. The

90 collaborations were also stratified by institution of family medicine researchers.

91

92 Statistical analyses

93 Descriptive statistics were presented. All calculations were performed with Microsoft Excel 2013.

95 RESULTS

96 From 1993 to 2014, family medicine researchers in Taiwan had authored 2,107 articles. The

97 annual publication counts in the early 5 years were less than 10 articles per year, increased to 101

98 articles in 2007 and continuously grew to be more than 200 articles in 2011.

99 Among 1,217 articles from 2010 to 2014, family medicine researchers in Taiwan acted as the

100 first authors in 443 (36.4\%) articles, corresponding authors in 347 (28.5\%) articles, and both the 
101 first and corresponding authors in 198 articles (16.3\%). The overwhelming majority of

102 publications were results of collaboration and only 22 articles came from a single family

103 medicine department. Interdisciplinary collaboration existed in 1,185 (97.3\%) articles,

104 interinstitutional in $1,012(83.2 \%)$ and international in $142(11.7 \%)$. In $1,002(82.3 \%)$ articles

105 there were both interdisciplinary and interinstitutional collaborations. All 142 articles with

106 international collaboration had also interdisciplinary and interinstitutional collaborations (Fig. 1).

107 From 2010 to 2014, family medicine researchers from 71 institutions in Taiwan had published

108 articles indexed in the Web of Science. All articles had on average an IF of 2.9 (SD 2.2) and only

$109112(9.2 \%)$ articles had an IF $>=5$. Table 1 showed the paper counts with mean journal IF in the

110 top 20 institutions. Taipei Veterans General Hospital was most productive with 215 (17.7\%)

111 articles, followed by Chung Shan Medical University Hospital with 140 (11.5\%) and China

112 Medical University Hospital with 136 (11.2\%). Taipei Veterans General Hospital had also the

113 largest number of papers with IF $>=5$ (39 articles).

114 Public health is the discipline with which family medicine researchers in Taiwan mostly

115 collaborated (493 articles, $40.5 \%$ ), almost two and a half times as much as that with internal

116 medicine (16.4\%). Most institutions with family medicine researchers in Taiwan had a high

117 percentage of interdisciplinary and interinstitutional collaborations, with the exception of

118 National Cheng Kung University Hospital (interinstitutional collaboration in only $53.7 \%$ of 
119 articles) (Table 1). The Chang Gung Memorial Hospital had the highest percentage (31.1\%) of

120 international collaboration.

121 Table 2 showed the geographic distribution of international collaboration of family medicine

122 researchers in Taiwan. Most research partners existed in North America (84 articles), followed

123 by Europe (43) and Asia (26). The United States (75 articles), the United Kingdom (21) and the

124 People's Republic of China (20) were the top three countries with which family medicine

125 researchers in Taiwan had collaborated.

126

127 DISCUSSION

128 Our study was a descriptive analysis to investigate the collaboration of family medicine research

129 in Taiwan. The collaborative activity was based on authorship (Katz \& Martin, 1997) and the

130 collaborative types were divided into interdisciplinary, interinstitutional and international. We

131 found most publications by family medicine researchers in Taiwan had interdisciplinary and

132 interinstitutional collaboration. However, the collaboration of family medicine researchers in

133 Taiwan with family medicine colleagues of other domestic or foreign institutions was relatively

134 low.

135 Our results showed almost all publications from family medicine researchers in Taiwan had

136 collaborative relationship with other disciplines and were published in subject categories other 
137 than "primary health care." This phenomenon might be related to the influence of impactor

138 factors and publication volumes which are relatively low in family medicine journals (Lin et al.,

139 2006). The family medicine research always faces great challenges. In 2003, the World

140 Organization of Family Doctors (WONCA) conference recommended to build the research

141 capacity of this discipline (van Weel \& Rosser, 2004). Voorhees et al reported that only $4.9 \%$ of

142 the 28,505 board-certified family physicians in the United States had spent time for research

143 (Voorhees et al., 2013). Lack of time, funding support and resources blocked the development of

144 family medicine researchers and the collaborative relationship with other disciplines might help

145 to solve the problem (Beasley, 2011). Interdisciplinary collaboration did offer better accessibility

146 of resources (Beasley, 2011). In Sweden, the National Research School in General Practice

147 provided a creative environment for multidisciplinary researches (Horton, 2014). On the other

148 side, the research groups among family medicine researchers also flourished worldwide, e.g. the

149 South Asia Primary Care Research Network, the North America Primary Care Research Group,

150 and the European General Practice Research Network (Kidd et al., 2014). However, our study

151 revealed that the research network among family medicine researchers in Taiwan didn't develop

152 well and the thriving research output was attributed to the interdisciplinary activities.

153 Few studies had analyzed the collaborative disciplines of family medicine researchers. Our

154 study displayed that public health was the most common collaborative discipline of family 
155 medicine researchers in Taiwan. Family medicine and public health are alleged to be natural

156 allies (Campos-Outcalt, 2004). Public health promotes the health of public, including

157 epidemiology and preventive medicine. The goal of public health is also pursued by family

158 physicians in the daily practice, e.g., health education, disease screening, immunization and

159 smoking cessation (Campos-Outcalt, 2004). It can be understood that the two disciplines

160 collaborate more effectively (Kempe et al., 2014).

161 A report showed that $15.6 \%$ articles in the SCI database were internationally co-authored

162 (Wagner \& Leydesdorff, 2005). In Taiwan, the share of clinical medicine researches with

163 international cooperation was 13.6\% during 1990-2004 (Chen et al., 2007). In our results, the

164 average international collaborative rate was $11.7 \%$. International research collaboration could

165 increase the scientific popularity and visibility (Persson, Glanzel \& Danell, 2004; Chinchilla-

166 Rodriguez et al., 2010). Articles with international collaboration were usually published in

167 journals with higher impact factors or more frequently cited (Chen et al., 2007; Persson, Glanzel

$168 \&$ Danell, 2004). In addition, collaboration among researchers with diverse scientific

169 backgrounds might provide more resources, enhance sharing and transfer of knowledge, skills

170 and techniques, and bring more stimulation and creativity (Katz \& Martin, 1997). On the other

171 hand, researchers might lose the true meaning of research if the purpose of collaboration was just

172 to get access to high IF journals. It would be thus hard to maintain the specificity of the 
173 discipline and country.

174 Special attention should be paid to Fig. 1 which showed that all international family medicine

175 researches in Taiwan belonged to interdisciplinary articles. That is, family medicine researchers

176 in Taiwan did not join the research network of family medicine in other countries or international

177 organizations. Because the research materials of family medicine usually come from daily

178 primary care (de Lusignan et al., 2011), the differences of healthcare systems might hinder the

179 data integration in international research. Even though WONCA has organized several working

180 panels to actively promote international collaboration, family medicine researchers in Taiwan

181 didn't seem to have taken advantage of these opportunities or achieved successful outcomes.

182 The international collaboration of family medicine researchers in Taiwan was not

183 geographically limited. In the past the collaborative research activities could be affected by the

184 geographic distance and in the internet era this limitation was effaced (Katz \& Martin, 1997).

185 Situated in Far East, Taiwan had closer collaboration with North America and Europe than with

186 Asian countries. Even though Taiwan and the People's Republic of China share the same cultural

187 origin, the collaboration of both sides was far from satisfactory. The undesirable collaboration

188 also applied to Japan which had colonized Taiwan for fifty years. Paraje G et al. had reported

189 similar results. In the Western Pacific region, the intra-regional collaboration of health research

190 was low. Countries with large research output (e.g., Japan, China) collaborated more with high- 
191 income countries from other regions (Paraje, Sadana \& Salmela, 2009).

192 Our study revealed the insufficient collaboration of family medicine researchers in Taiwan

193 with family medicine colleagues of other institutions, either domestic or foreign. It also existed

194 in other specialties and countries (Paraje, Sadana \& Salmela, 2009). The WONCA conference in

1952003 developed some recommendations to solve this problem. One major step was to organize a

196 platform for communication among family medicine researchers, either provided by national

197 medical associations, university departments of family medicine, or family medicine research

198 institutes. The collaborative platform could be extended from local to national and regional

199 levels (van Weel \& Rosser, 2004).

200 There were some limitations in our study. Our search criteria were "family medicine" AND

201 "Taiwan" in the address field of Web of Science. If a department with family physicians carried

202 other names, e.g., community medicine, its publications might be missed. The possibility should

203 be low because all family medicine departments of larger academic medical centers in Taiwan

204 were enrolled in our study. Furthermore, we analyzed the collaborative activity according to the

205 affiliations of authors. Authors with multiple affiliations might result in overestimation of

206 collaboration. The possibility should be low because multiple authorship prevailed so that

207 interpersonal collaboration in this situation would usually imply interdisciplinary or

208 interinstitutional collaboration. In spite of these limitations, our article was the first study to 
209 report the collaborative patterns of family medicine researchers from interdisciplinary,

210 interinstitutional and international levels. Our finding was helpful to the discussions of current

211 scientific research collaborative status.

212

\section{CONCLUSIONS}

214 Previous study (Lin et al., 2006) found that the academic performance assessment caused family

215 medicine researchers in Taiwan to publish more papers in non-family medicine, foreign, English-

216 language, and SCI-indexed journals. Our current study revealed that family medicine researchers

217 in Taiwan rapidly expanded their publications through a high degree of interdisciplinary and

218 interinstitutional collaboration. However, the collaboration of family medicine researchers in

219 Taiwan with family medicine colleagues of other institutions, either domestic or foreign, lagged

220 far behind. The organization of a platform to enhance the communication among family

221 medicine researchers might be a solution.

222

\section{ACKNOWLEDGEMENTS}

224 The authors would like to thank Ching Wen Liang for computer graphics. 
227 Abdulmajeed A. A., Ismail M. A., Nour-Eldein H. 2014. Research publications in medical

228 journals (1992-2013) by family medicine authors - suez canal university-egypt. Journal of

229 Family Medicine and Primary Care 3: 368-373. DOI 10.4103/2249-4863.148112.

230 Beasley J. W. 2011. Collaboration to support family medicine research. Family Medicine 43: 51.

231 Bolon S. K., Phillips R. L. 2010. Building the Research Culture of Family Medicine With

232 Fellowship Training. Family Medicine 42: 481-487.

233 Campos-Outcalt D. 2004. Public health and family medicine: an opportunity. The Journal of the

234 American Board of Family Practice 17: 207-211.

235 Chen T. J., Chen Y. C., Hwang S. J., Chou L. F. 2007. International collaboration of clinical

236 medicine research in Taiwan, 1990-2004: a bibliometric analysis. Journal of the Chinese

237 Medical Association 70: 110-116. DOI 10.1016/S1726-4901(09)70340-5.

238 Chinchilla-Rodriguez Z., Vargas-Quesada B., Hassan-Montero Y., Gonzalez-Molina A., Moya-

239 Anegon F. 2010. New approach to the visualization of international scientific collaboration.

240 Information Visualization 9: 277-287. DOI 10.1057/ivs.2009.31.

241 de Lusignan S., Pearce C., Shaw N. T., Liaw S. T., Michalakidis G., Vicente M. T., Bainbridge M.,

242 International, European Medical Informatics A., Federation Primary Care Informatics

243 Working G. 2011. What are the barriers to conducting international research using routinely

244 collected primary care data? Studies in Health Technology and Informatics 165: 135-140. 
245 Department of Health, Executive Yuan. 1988. Diplomate specialization and examination

246 regulations: legislative history. Available at

247 http://law.moj.gov.tw/Eng/LawClass/LawHistory.aspx?PCode=L0020028 (accessed 24 Aug

$248 \quad 2015)$

249 Horton R. 2014. Offline: How to save primary care research. Lancet 384: 1082.

250 Katz J. S., Martin B. R. 1997. What is research collaboration? Research Policy 26: 1-18. DOI

$251 \quad 10.1016 / \mathrm{s} 0048-7333(96) 00917-1$.

252 Kempe A., Albright K., O'Leary S., Kolasa M., Barnard J., Kile D., Lockhart S., Dickinson L. M.,

253 Shmueli D., Babbel C., Barrow J. 2014. Effectiveness of primary care-public health

254 collaborations in the delivery of influenza vaccine: a cluster-randomized pragmatic trial.

255 Preventive medicine 69: 110-116. DOI 10.1016/j.ypmed.2014.08.019.

256 Kidd M., Manning G., Howe A., Qidwai W., Beasley J. W., van Weel C. 2014. Primary care

257 research. Lancet 384: 1671-1672. DOC 10.1016/S0140-6736(14)62031-6.

258 Lin M. H., Chen L. K., Hwang S. J., Weiss B. D., Chou L. F., Chen T. J. 2006. The impact of impact

259 factor on small specialties: A case study of family medicine in Taiwan. Scientometrics 66:

260 513-520. DOI 10.1007/s11192-006-0037-9.

261 Lin M. H., Hwang S. J., Hwang I. H., Chen Y. C. 2014. Family medicine publications in Taiwan: an

262 analysis of the Web of Science database from 1993 to 2012. Journal of the Chinese Medical 
Association 77: 583-588. DOI 10.1016/j.jcma.2014.05.015.

264 Ministry of Health and Welfare. 2015. Medical professionals practice data. Available at

265 http://data.gov.tw/node/8569 (accessed 24 Aug 2015)

266 Paraje G1, Sadana R, Salmela R. 2009. Collaboration and "visibility" of health research in the

267 Western Pacific region. Asia-Pacific Journal of Public Health 21:128-136. DOI

$268 \quad 10.1177 / 1010539509331983$.

269 Parchman M., Katerndahl D., Larme A. 2003. Family medicine and research: from here to 270 eternity. Family Medicine 35: 291-295.

271 Persson O., Glanzel W., Danell R. 2004. Inflationary bibliometric values: The role of scientific

272 collaboration and the need for relative indicators in evaluative studies. Scientometrics 60: 421-432. DOI 10.1023/B:SCIE.0000034384.35498.7d.

274 Taiwan Association of Family Medicine. 2015. The list of attending physicians in training

275 hospital. Available at https://www.tafm.org.tw/ehc-

276 tafm/s/w/train/trainYearDateDrU/trainYearDateDrU/20/1 (accessed 24 Aug 2015)

277 van Weel C., Rosser W. W. 2004. Improving health care globally: a critical review of the

278 necessity of family medicine research and recommendations to build research capacity.

279 Annals of Family Medicine 2: S5-16. DOI 10.1370/afm.194.

280 Voorhees J. R., Xierali I. M., Bazemore A. W., Phillips R. L., Jr., Jaen C. R., Puffer J. C. 2013. A 
281 small percentage of family physicians report time devoted to research. Journal of the

282 American Board of Family Medicine 26: 7-8. DOI 10.3122/jabfm.2013.01.120125.

283 Wagner CS, Leydesdorff L. 2005. Mapping the network of global science: comparing

284 international co-authorships from 1990 to 2000. International Journal of Technology and

285 Globalisation 1: 185-208.

286 
Figure 1 (on next page)

Interdisciplinary, interinstitutional and international collaboration of family medicine researchers in Taiwan from 2010 to 2014. 


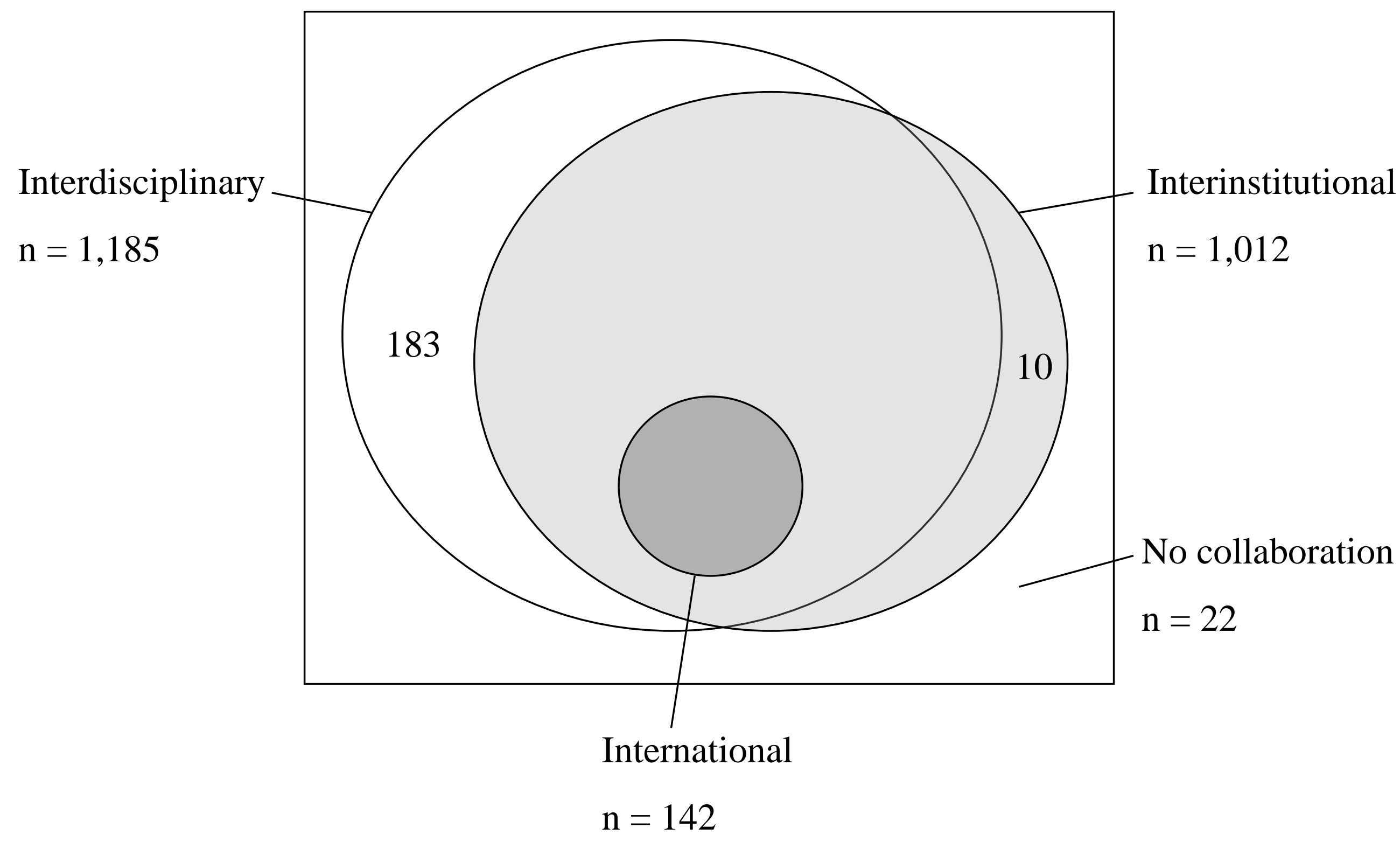




\section{Table $\mathbf{1}$ (on next page)}

The interdisciplinary, interinstitutional and international collaboration and the mean IF of the top 20 institutions of family medicine researchers in Taiwan from 2010 to 2014. 
Table 1 The interdisciplinary, interinstitutional and international collaboration and the mean IF of the top 20 institutions of

2 family medicine researchers in Taiwan from 2010 to 2014.

\begin{tabular}{|c|c|c|c|c|c|c|}
\hline \multirow{2}{*}{$\begin{array}{l}\text { Institutions of family medicine } \\
\text { researchers }\end{array}$} & \multirow{2}{*}{$\begin{array}{l}\text { No. of } \\
\text { articles }\end{array}$} & \multirow{2}{*}{$\begin{array}{c}\text { IF } \\
(\text { Mean } \pm \text { SD })\end{array}$} & \multirow{2}{*}{$\begin{array}{c}\text { No. of articles } \\
\text { with } \text { IF }>=5 \\
(\%, n=112)\end{array}$} & \multirow{2}{*}{$\begin{array}{c}\text { Interdisciplinary } \\
\text { No. of articles } \\
(\%)\end{array}$} & \multirow{2}{*}{$\begin{array}{c}\text { Interinstitutional } \\
\text { No. of articles } \\
(\%)\end{array}$} & \multirow{2}{*}{$\begin{array}{c}\text { International } \\
\text { No. of articles } \\
(\%)\end{array}$} \\
\hline & & & & & & \\
\hline Taipei Veterans General Hospital & 215 & $3.45 \pm 2.40$ & $39(34.8)$ & $214(99.5)$ & $169(78.6)$ & $24(11.2)$ \\
\hline $\begin{array}{l}\text { Chung Shan Medical University } \\
\text { Hospital }\end{array}$ & 140 & $2.84 \pm 3.22$ & $8(7.1)$ & $140(100)$ & $104(74.3)$ & $5(3.6)$ \\
\hline $\begin{array}{l}\text { National Taiwan University } \\
\text { Hospital }\end{array}$ & 111 & $2.87 \pm 2.22$ & $8(7.1)$ & $108(97.3)$ & $94(84.7)$ & $18(16.2)$ \\
\hline $\begin{array}{l}\text { National Cheng Kung University } \\
\text { Hospital }\end{array}$ & 67 & $3.34 \pm 2.25$ & $10(8.9)$ & $54(80.6)$ & $36(53.7)$ & $8(11.9)$ \\
\hline Chang Gung Memorial Hospital & 45 & $2.76 \pm 1.70$ & $6(5.4)$ & $44(97.8)$ & $38(84.4)$ & $14(31.1)$ \\
\hline Buddhist Tzu Chi General Hospital & 35 & $2.37 \pm 1.14$ & 0 & $33(94.3)$ & $26(74.3)$ & $7(20.0)$ \\
\hline Taipei City Hospital & 32 & $2.84 \pm 2.36$ & $2(1.8)$ & $32(100)$ & $32(100)$ & $7(21.9)$ \\
\hline $\begin{array}{l}\text { Taichung Veterans General } \\
\text { Hospital }\end{array}$ & 28 & $2.48 \pm 1.41$ & $1(0.9)$ & $28(100)$ & $26(92.9)$ & $2(7.1)$ \\
\hline Tri-Service General Hospital & 27 & $2.81 \pm 1.55$ & $2(1.8)$ & $26(96.3)$ & $20(74.1)$ & $3(11.1)$ \\
\hline Chi Mei Medical Center & 26 & $2.48 \pm 1.27$ & $1(0.9)$ & $26(100)$ & $25(96.2)$ & $4(15.4)$ \\
\hline Cardinal Tien Hospital & 25 & $2.27 \pm 1.35$ & $1(0.9)$ & $25(100)$ & $22(88.0)$ & $1(4.0)$ \\
\hline
\end{tabular}




\begin{tabular}{|c|c|c|c|c|c|c|}
\hline Armed Forces General Hospital & 19 & $1.97 \pm 0.94$ & 0 & $17(89.5)$ & $15(78.9)$ & 0 \\
\hline Mackay Memoral Hospital & 17 & $1.58 \pm 1.46$ & 0 & $16(94.1)$ & $13(76.5)$ & 0 \\
\hline $\begin{array}{l}\text { Kaohsiung Veterans General } \\
\text { Hospital }\end{array}$ & 16 & $1.56 \pm 1.09$ & 0 & $16(100)$ & $16(100)$ & $2(12.5)$ \\
\hline Cathay General Hospital & 12 & $3.95 \pm 2.25$ & $2(1.8)$ & $12(100)$ & $11(91.7)$ & 0 \\
\hline $\begin{array}{l}\text { Ministry of Health and Welfare, } \\
\text { Taichung Hospital }\end{array}$ & 12 & $1.72 \pm 1.21$ & 0 & $12(100)$ & $12(100)$ & $1(8.3)$ \\
\hline
\end{tabular}

3 
Table 2 (on next page)

Distribution of international collaboration of family medicine researchers in Taiwan,stratified by continent and country. 
1 Table 2 Distribution of international collaboration of family medicine researchers in

2 Taiwan, stratified by continent and country.

\begin{tabular}{|c|c|c|c|}
\hline Continent & No. of articles & Country & No. of articles \\
\hline \multirow[t]{2}{*}{ North America } & 84 & United States & 75 \\
\hline & & Canada & 11 \\
\hline \multirow[t]{14}{*}{ Europe } & 43 & United Kingdom & 21 \\
\hline & & Germany & 19 \\
\hline & & Netherlands & 6 \\
\hline & & Belgium & 3 \\
\hline & & France & 3 \\
\hline & & Poland & 2 \\
\hline & & Italy & 2 \\
\hline & & Czech Republic & 1 \\
\hline & & Hungary & 1 \\
\hline & & Sweden & 1 \\
\hline & & Spain & 1 \\
\hline & & Switzerland & 1 \\
\hline & & Bulgaria & 1 \\
\hline & & Norway & 1 \\
\hline \multirow[t]{10}{*}{ Asia } & 26 & Peoples R China & 20 \\
\hline & & Japan & 7 \\
\hline & & Malaysia & 4 \\
\hline & & South Korea & 3 \\
\hline & & Indonesia & 3 \\
\hline & & Singapore & 3 \\
\hline & & India & 2 \\
\hline & & Philippines & 2 \\
\hline & & Thailand & 2 \\
\hline & & Israel & 1 \\
\hline \multirow[t]{2}{*}{ Oceania } & 9 & Australia & 8 \\
\hline & & New Zealand & 1 \\
\hline \multirow[t]{3}{*}{ Latin America } & 4 & Mexico & 2 \\
\hline & & Nicaragua & 1 \\
\hline & & Brazil & 1 \\
\hline
\end{tabular}


